\title{
Transition to Latin Alphabet (20s of the Twentieth Century) Modern Reality Is a Result of Historical Events
}

\author{
Kazimi Parviz Firudın Oqlu \\ Correspondence: Kazimi Parviz Firudın Oqlu, Baku State University, Associate Professor, Doctor of Philosophy, \\ Russia. Email: pkazimi@mail.ru, +994553704141. ORCID: -Parviz Kazimi4[0000-0001-5577-4773]
}

Received: May 9, 2021

doi:10.5430/elr.v10n2p38
Accepted: May 30, 2021

Online Published: June 6, 2021

URL: https://doi.org/10.5430/elr.v10n2p38

\begin{abstract}
In the 1920s, a number of processes began to take place in the new structure that arose in the collapsed geography of the Russian Empire. One of these processes was the transition of peoples to the "Latin" alphabet, which is also called "Latinization" in the world scientific literature. One of the least covered problems of the processes that took place in different geographical regions after the collapse of empires is the problem of "Latinization". Thus, "Latinization", which played an important role in world cultural history, is still interpreted by various sources and researchers without understanding the essence of the problem, and reflects an important historical event in political and national interests.

The entry of the modern world into the global information space with the help of the Latin alphabet has revived the attitude of people to the Latin alphabet. A number of countries are being taught two alphabets in order to preserve the national alphabet, and in some countries they are working to transform the national alphabet. Of course, rational thinking sees and accepts the irreversible process of transition to a single global alphabet. While this trend stems from the need for technology in the 21st century, it was high on the agenda in the 1920s for ideological reasons. Experts have the mass transition of people to the "Latin alphabet" that took place in the 20s of the last century as a process of Latinization. Researchers cannot give an unambiguous answer, what was the transition of the Turkic peoples to a single alphabet? Was this an appeal of the Muslim peoples to a single alphabet? Or was it the USSR's search for a single means of communication for the world "proletariat"?
\end{abstract}

The article will attempt to explain the historical context of the Latinization process, the role of the Azerbaijani factor in this process and the essence of various tasks.

Keywords: Latin alphabet, Azerbaijani alphabet, Turkic alphabet, alphabet of revolution

\section{Introduction}

In the 1920s, a number of processes began to take place in the new structure that arose in the collapsed geography of the Russian Empire. One of these processes was the transition of peoples to the Latin alphabet, which is also called Latinization in the world scientific literature. Until now, various sources and researchers comment on this problem without understanding its essence, and portray an important event in the history of culture in their political and national interests. However, in the 1920s, Latinization was called the alphabet of the revolution.

The process of historical Latinization, which played an important role in the cultural development of modern society, is a global cultural event. Religious, national and regional assessments do not reflect the true nature of the event.

\section{Main Problems}

The entry of the modern world into the global information space with the "Latin alphabet" has revived people's attitude to the Latin alphabet. Some countries are organizing teaching using two alphabets in order to preserve the national alphabet, and in some countries they are working on converting the national alphabet. Of course, rational thinking sees and accepts the irreversible process of transition to a single global alphabet. If this trend stems from the need for modern technology in the 21 st century, it was on the agenda in the 20 s for ideological reasons. Experts associate the mass transition of peoples to the Latin alphabet with the process of romanization of the 1920s.

Researchers cannot give an unambiguous answer that this was the transition of the Turkic peoples to a single alphabet? Was this an appeal of the Muslim peoples to a single alphabet? Or was it the USSR's search for a single means of communication for the world proletariat? 
We will try to answer the real essence of the romanization process by analyzing historical documents and various approaches.

In 1921, the Latin alphabet was introduced in Azerbaijan, in the North Caucasus - Ingushetia, North Ossetia and Kabardino-Balkaria. During the first Turkological congress (1926, Baku), an organization called the All-Union Central Committee of the New Turkish Alphabet was created. This body held its first plenum in Baku in 1927 and adopted a draft unification of the 34-letter alphabet for the Turkic people.

On August 8, 1929, the Central Executive Committee of the USSR issued an order "New Latinized alphabet of the Arabic-writing peoples of the USSR", and all printing houses, publishing houses and educational institutions were to officially switch to the Latin alphabet. Beginning in 1930, non-Muslim peoples in Russia also began to switch to the Latin alphabet.

Between 1920 and 1936, 50 of the 72 peoples of the Soviet Union switched to the Latin alphabet. This included peoples who wrote in the Arabic alphabet, and those who did not have an alphabet, as well as peoples who adopted the Cyrillic alphabet. Also, those who are looking for a "Turkish element" should know that many non-Turkic Caucasian and Siberian peoples happily adopted the Latin alphabet. The peoples of Siberia and the Caucasus easily abandoned the Cyrillic alphabet, which was "prepared and adopted under the pressure of the church" by the missionaries of the Russian Orthodox Church.

In the late 1930s, Stalin stopped the project of translating the Slavic people into the Latin alphabet, and from 1936 he demanded that the peoples switch to the Cyrillic alphabet. This process ended in 1939. It is noteworthy that the peoples not covered by romanization also do not participate in the transition to the Cyrillic alphabet. These include German, Georgian, Armenian, Yiddish, followed by Finnish, Polish, Latvian, Estonian and Lithuanian.

In the mid-1930s, the Georgian and Armenian church alphabets were declared the national alphabet. These peoples did not switch to the Latin alphabet and did not switch to the Cyrillic alphabet. The Baltic republics were not yet formed at this time. On the other hand, the Cyrillic alphabet was no longer considered the church alphabet due to reforms in the "early years" of Soviet power.

The general ideology was as follows: those who had a "national alphabet" retained their alphabets, and peoples who did not have a national alphabet were forced to switch to the Cyrillic alphabet.

\section{Evaluation Errors}

In connection with the transition of peoples to the Latin alphabet, various scientific and social sources circulate various information, most of which have no scientific and historical basis. Information that serves opportunistic and political purposes is presented as scientific information.

The first congress of Turkologists, held in Baku in 1926, made the transition to the Latin alphabet internationalized. Although since 1919 there have been serious discussions in Azerbaijan about the transition to the Latin alphabet, practical work began in 1921. Because the Arabic alphabet is a problem in the writing process, the history of thought is very old.

During these years, Azerbaijani intellectuals realized that the transition of a small nation to the Latin alphabet would not solve the problem, and made efforts to internationalize this process.

Prominent Azerbaijani politician Nariman Narimanov held discussions with V.I. Lenin and A.V. Lunacharsky, the first minister of education of that time, on expanding the area of $\backslash u 200 b \backslash u 200 b$ the transition to the Latin alphabet. It should be noted that in the memoirs of A.V. Lunacharsky about the importance of switching to the Latin alphabet, you can find a lot of material.

The group of experts believes that the authorities did not interfere with the use of the Latin alphabet in order to accelerate the integration of Muslim peoples living on the territory of the Russian Empire into secularism (the European system of values). Since the Cyrillic alphabet personified the Russian Orthodox Church in the minds of the peoples of the Russian Empire, the central government did not participate in the process of education and enlightenment of the peoples. In regions with Islamic culture, the Arabic alphabet was taught in traditional schools, and the ideology of religion hindered the integration of the alphabet and languages. Therefore, the decision of the first congress to switch to the Latin alphabet was supported, and the central government did not interfere in this process.

Although a number of modern political scientists and publicists note the special role of Azerbaijan in the transition to the Latin alphabet in the USSR, they associate this with the transition of the Republic of Turkey to the Latin alphabet. A lot of articles have been written about this. Although it has no scientific or historical basis, this information is disseminated as "scientific information". There are those who put forward different conspiratorial views. 
The fact that in the process of romanization in the country the overwhelming majority of the Caucasian peoples switched to this alphabet, Georgia and Armenia retained the church alphabet as the national alphabet shows that these processes were not under the influence of the center. According to A.V. Lunacharsky, even Russians will gradually switch to the Latin alphabet and get rid of the Cyrillic alphabet of the Orthodox Church. The state project developed for this was canceled by Stalin in the early 1930s.

However, we believe that the transition to the Latin alphabet emerged as a result of the democratic process of the 1920s, and the national intelligentsia played an important role in this process.

The idea of romanizing the Russian alphabet (including, of course, Ukraine and Belarus) received a great impetus, thanks to the successes of romanizing the writing of people using Arabic script. The Russian intelligentsia of that time was of the opinion that "the Russian Cyrillic alphabet separates us not only from the West, but also from the East, which in many respects has awakened."

In the organization "Glavnauka" a large commission was created, a special commission with the participation of professors Zhirkov, Korinsky, Chelkunov and Yakovlev, who were instructed to formulate the principles that must be taken into account when building a new alphabet. This commission determines the recommended proposals for the transition from Cyrillic to Latin as follows:

1. Combine with international graphic elements of the East and West and use many letters of the Latin alphabet without modification.

2. Do not enter "double" letters in the alphabet.

3. Do not enter letters derived from the Russian alphabet.

4. Do not include accented letters in the alphabet.

5. Create the letters with the symbols written "without taking hands off".

6. The number of letters in the alphabet should be less than the existing Russian language.

8. Each letter must have only one sound expression.

9. Any sound combination must be recorded in only one way, and so on.

\section{Historical Analysis}

In the geography of Islamic culture, the technique of literary and scientific writing in the national languages in the Arabic alphabet was not regulated by special grammatical norms. At the dawn of Islamic culture, not only was it impossible to write in the Arabic alphabet in national languages, but even the needs of the Arabic language itself were not fully satisfied. Reforms of the alphabet at different times caused clashes between conservatives and reformers. The most powerful weapon of the conservatives was not that the alphabet was the Arabic alphabet (conventionally called the "Arabic alphabet"), but that the Word of God was written on it.

The fundamental difference between Turkish and Indo-European and Semitic languages is that Turkish is agglutinative. A particular difficulty in the formation of a written monument written in Turkish using the Arabic alphabet was the lack of appropriate letters to designate sounds only in the Arabic alphabet.

The search for the perfect alphabet has created different landscapes in different parts of the world. As a result of this process, the Japanese (who had an agglutinative language) today uses three alphabets. Although Koreans (who had an agglutinative language) were influenced by Chinese characters for a long historical period, they reformed their alphabets in the 15th century, adapting the Chinese character system to their national languages. The Chinese, however, did not accept the square alphabet, which Kublai Khan reformed in the 13th century and introduced into circulation throughout China. In multinational China, hieroglyphic writing served as a means of international communication. For example, the character for mountain was shan in Chinese, yama in Japanese, and san in Korean.

Historical sources confirm that in ancient times, writing a speech was a sacred event. It is no coincidence that the oldest sources relate to religious themes. In Azerbaijan, the concept of "writing on the forehead" means that the letter even has a mystical meaning. Therefore, not everyone can read and write, and "those who read and write were not like everyone else."

From the third millennium BC, cuneiform, inherited from the Sumerians, was used throughout Asia Minor. At the same time, there are many sources with cuneiform writing in ancient Semitic languages. BC. In the first millennium BC, the Phoenician phonetic alphabet will form the basis of the Greek alphabet, then the Latin alphabet, the Aramaic, then the early Semites, and the ancient Pahlavites will use the Aramaic alphabet. These alphabets did not (or will partially) have 
vowels, as in the modern Arabic alphabet. Do note that all of these languages are inflectional languages.

The Sumerians switched from "drawing" to cuneiform, and later the Akkadians, Assyrians, Babylonians and all the peoples of Mesopotamia began to write based on this alphabet. The creation by the Phoenicians of a phonetic alphabet based on this alphabet, as well as its use by the Arameans, the use of the Aramaic language by the Jews and the Pahlavi, and the derivation of the Latin alphabet from Greek show that two concepts are manifested in the formation of the writing system.

I - Creating a perfect writing system,

II - Acquiring opportunities for national (tribal and group) self-isolation.

There is a lot of information in world history about changing the alphabet or reforming its internal structure. However, even the oldest examples of the alphabet today, unfortunately, are far from perfect, despite many reforms.

On March 21, 1919, by the decree of the government of the Azerbaijan Democratic Republic, the Ministry of Public Education was instructed to create a special government commission on the reform of the Arabic alphabet and submit the proposals prepared by the commission to the Council of Ministers for consideration. According to this decision, a special commission on the reform of the Arabic alphabet was created under the Ministry of Public Education under the chairmanship of a member of the government of the Azerbaijan Democratic Republic Khudadat bey Malik-Aslanov. The reform of the alphabet, first of all, was supposed to directly serve the implementation of the tasks facing the state in the field of education, nationalization of public education. The commission, acting with the attention and care of the government of the Azerbaijan Democratic Republic, soon prepared and presented to the government a number of projects of the alphabet.

Among these projects, the version prepared by the teacher, Abdullah bey Efendizade, was approved and adopted as the basis for the new alphabet. A. Afendizadeh also published in Baku in 1919 the textbook "The Last Turkish Alphabet", dedicated to the reform of the alphabet, especially the need to switch to the Latin alphabet. In the textbook, he first compared the Arabic and Latin alphabets, arguing that the former is incompatible with our native language, and the latter is more consistent with rich linguistic facts. The first practical steps taken by the government of the Azerbaijan Democratic Republic in the field of alphabet reform were incomplete as a result of the April occupation.

In 1921, the idea of reforming the alphabet, which was already on the verge of implementation during the time of the Azerbaijan Democratic Republic, was returned to Soviet Azerbaijan. After a wide discussion of this issue, a new decree signed by Nariman Narimanov was created by the Committee for the reform of the alphabet in Azerbaijan according to the new Turkish alphabet. The draft of the Azerbaijani alphabet based on the Latin alphabet prepared by the committee has been published in the "Yeni Yol" newspaper for public discussion.

In 1926, the 1st Turkic Congress was held in Baku. At this congress, the transition of the Turkic peoples to the Latin alphabet was considered and a decision was made. For the first time, this congress became a platform that clearly expressed the integration aspirations of the Turkish people. It was stated that the Latin alphabet can express the features of the Turkic languages and is a hope for the historical integration of peoples living in the great geography of this alphabet. After tense and long discussions, in 1929, Azerbaijan completely switched to the Latin alphabet. Thus, one of the tasks set by the Azerbaijan Democratic Republic was completed.

In Turkey, on November 1, 1928, with the adoption of the Law No. 1353 on the Approval and Application of New Turkish Letters, the process of introducing a new alphabet began. With the passage of this law, the Turkish alphabet, based on Latin letters, took effect in place of the Arabic letters used until that day. In addition, reading the letters of the Turkish alphabet was different from reading the letters of Western languages and Arabic. This process was led by the great Ataturk.

Consequently, the transition to the Latin alphabet did not take place, because the Turkish Republic adopted this alphabet, and other Turkic peoples also adopted this alphabet. On the contrary, this alphabet was adopted because it responded to the historical search and wide integration of the Turkic peoples.

The essence of Soviet power, created in the 1930s, has changed. This was no longer the Union of Soviet Socialist Republics, but a model of an authoritarian state dictated by Moscow. The Latin alphabet, adopted by the Turkic peoples, was replaced by the Cyrillic alphabet at the behest of Moscow, and adventurous ideas "Soviet people" began to be created.

\section{Conclusion}

The idea that "the peoples did not create the alphabet, the founders of the alphabet were religious communities and religious organizations" is often found in the works of experts at the beginning of the 21 st century. Therefore, today 
there is a tendency to idolize the alphabet, giving it the status of a national alphabet, to ignore the difficulties that arise when expressing thoughts, and to consider it inviolable.

In 1991, after the collapse of the USSR, five independent Turkic states were formed: Azerbaijan, Kazakhstan, Kyrgyzstan, Uzbekistan and Turkmenistan. Among them, first of all, Azerbaijan, Uzbekistan and Turkmenistan switched to the Latin alphabet, while Kazakhstan and Kyrgyzstan took some time to switch to the Latin alphabet. Republics in the Russian Federation such as Bashkortostan, Chuvashia, Tatarstan, Yakuts, Khakassia, and Tuva continued to use the Cyrillic alphabet. Thus, the Azerbaijani language chose the path of integration with the Latin script, completing a complex and difficult historical search in the group of Turkic languages, and this path was adopted as the common choice of the Turkic-speaking peoples. As a result of this historic choice, the language now requires rapid industrialization.

In the globalized world of the last thirty years, communication, "language and alphabet" is going through new tests and new exams.

\section{Reference}

150 languages and politics: 1917-1997. Sociolinguistic problems of the USSR and the post-Soviet space. M.: Institute of Oriental Studies RAS. 1997.192 s. ISBN 5-89282-022-X (2nd edition, supplemented (1917-2000). Moscow: Kraft + Institute of Oriental Studies RAS, 2000. 224 p.)

Agha, S. L. (01.06.2011). Simplify development in Turkish. Language Association Publications. p. 156. ISBN 9757495208.

Alpatov, V. (2002). Repressed Turkology. Moscow: Eastern Literature, 2002.296 p. (together with F. D. Ashnin and D. M. Nasilov).

https://en.wikipedia.org/wiki/Manixeizm

https://lenta.ru/articles/2017/05/23/latin/

https://ru.wikipedia.org/wiki/\%D0\%93\%D0\%BD\%D0\%BE\%D1\%81\%D1\%82\%D0\%B8\%D1\%86\%D0\%B8\%D0\% B7 \% D0\% BC

https://w.histrf.ru/articles/article/show/mitraizm

https://www.youtube.com/watch?v=nrHBC1OibYs

Kazimi, P. F. (2018). Information Engineering. Baku, translator, 2018, 260 p.

Khalafov, A. A. (2013). Library and Society. Baku, Azerneshr, 2013, 360 p.

Kramer, S. (2009). History begins with the Sumerians. Baku, Translator, 2009.280 p.

Order of the President of the Republic of Azerbaijan "On improving the use of the state language." http://www.eqanun.az/framework/3568

\section{Copyrights}

Copyright for this article is retained by the author(s), with first publication rights granted to the journal.

This is an open-access article distributed under the terms and conditions of the Creative Commons Attribution license (http://creativecommons.org/licenses/by/4.0/). 